REVISTA DE DERECHO UNED, núm. 2, 2007

\title{
EL RÉGIMEN REGISTRAL DE LA TUTELA PREVENTIVA
}

\author{
M. ${ }^{\mathrm{a}}$ Fernanda Moretón SANZ*
}

Resumen: Desde que se aprobó en 1889 el Código civil español, fue contemplada la necesidad de que los actos concernientes al estado civil constasen en el Registro destinado a este efecto. Antes de la entrada en vigor del Código civil, la Ley provisional del Registro Civil de 1870 asumió las funciones desempeñadas, hasta entonces, por los registros parroquiales de la Iglesia católica. Al día de hoy es la Ley del Registro Civil de 8 junio 1957 la que determina el objeto y sistema de publicidad registral, si bien esta última norma, hecha al amparo de los principios imperantes en su momento, ha sido sometida a una completa revisión para adaptarla a la Constitución de 1978. Adicionalmente a estas reformas, se ha de destacar la inestimable tarea de la denominada «jurisprudencia registral» de la Dirección General de los Registros y del Notariado emanada de sus Consultas, Resoluciones e Instrucciones dictadas en los últimos tiempos. En este trabajo y

* Profesora Asociada del Departamento de Derecho Civil de la UNED, Secretaria IDADFE (Instituto de Desarrollo y Análisis del Derecho de Familia en España), miembro del Grupo de Investigación consolidado "Protección de la persona», cuyo investigador principal es el Prof. Dr. D. Carlos LASARTE ÁLVAREZ. Este comentario forma parte de otro estudio más amplio sobre «La publicidad registral de los órganos tutelares» que verá la luz próximamente, y refleja parte de los aspectos tratados en la ponencia presentada y defendida en la "Jornada Internacional en conmemoración a los veinte años del Código civil cubano", siendo uno de los resultados del Proyecto de Investigación I+D+I del Ministerio de Trabajo y Asuntos Sociales. Secretaría de Estado de Servicios Sociales, Familia y Discapacidad. IMSERSO, que lleva por título «Reformulación de la incapacitación judicial ante las Políticas públicas de atención prioritaria a la dependencia: relevancia de las personas jurídicas públicas» (Orden TAS/1.588/2005, de 20 de mayo), siendo investigador responsable mi Maestro, el Profesor Carlos LASARTE ÁLVAREZ, Catedrático de Derecho civil de la UNED (España). 
con estos antecedentes, destacamos los efectos de la Resolución de la Dirección General de los Registros y del Notariado de 19 de junio de 2006 ya que, al resolver un recurso sobre anotación de tutela, clarifica la publicidad que hayan de recibir los cargos tutelares, resultando ser objeto de inscripción su constitución, frente a la indicación de la designación preventiva, hecha al margen de la del nacimiento.

Abstract: Since it was approved in 1889 the spanish Civil Code, it was contemplated the necessity that the acts to the civil state in the Registry dedicated to this effect. Before the to go into effect of the Civil Code, the provisional Law of the Civil Registry of 1870 assumed the carried out functions, until then, for the parochial registrations of the Catholic Church. To today's day it is the Law of the Civil Registration of 8 June 1957 the one that determines the object of publicity, although this last norm, made to the help of the prevailing principles in their time, it has been subjected to a complete revision to adapt it to the Constitution of 1978 . Additionally to these reformations, must highlight the task carried out by the Dirección General de los Registros y del Notariado with the content of the Consultations, Resolutions and Instructions published in the last times. In this work and with these antecedents we highlight the effects of the Resolution of June 192006 since, when solving a resource it has more than enough annotation of it guides, it clarifies the publicity that they must receive the guardian positions, turning out to be inscription object their constitution, in front of the indication of the preventive appointment, made to the margin of that of the birth.

Sumario: RESUMEN; 1. ORÍGENES Y REGULACIÓN NORMATIVA DEL REGISTRO CIVIL ESPAÑOL; 2. LA DEPENDENCIA ORGÁNICA DEL REGISTRO CIVIL AL MINISTERIO DE JUSTICIA: FUNCIONES DE LA DIRECCIÓN GENERAL DE LOS REGISTROS Y DEL NOTARIADO; 3. EL OBJETO DEL REGISTRO CIVIL Y LOS DIVERSOS TIPOS DE ASIENTOS REGISTRALES: EN PARTICULAR LA INSCRIPCIÓN Y LA INDICACIÓN; 4. LA REFORMA DEL CÓDIGO CIVIL ESPAÑOL EN MATERIA DE PODERES PREVENTIVOS Y AUTOTUTELA; 5. LA DIRECCIÓN GENERAL DE LOS REGISTROS Y DEL NOTARIADO ANTE LA TUTELA PREVENTIVA: LA CONSULTA DE 31 DE MAYO DE 2006 Y LA RESOLUCIÓN DE 19 DE JUNIO DE 2006; 6 REFLEXIONES SOBRE EL DOBLE SISTEMA REGISTRAL EN LA TUTELA PREVENTIVA Y AUTOTUTELA: LA DESIGNACIÓN Y EL EFECTIVO NOMBRAMIENTO; 7. CONCLUSIONES 


\section{ORÍGENES Y REGULACIÓN NORMATIVA DEL REGISTRO CIVIL ESPAÑOL}

Como ya hemos mencionado, y desde que se aprobara en $1889 \mathrm{el}$ todavía vigente Código civil español, se contempló en el Título XII con que se cierra el Libro primero De las personas, la necesidad de que los actos concernientes al estado civil consten en el Registro destinado a este efecto ${ }^{1}$.

En este sentido y para tener en cuenta algunas notas históricas relevantes, ha de recordarse que hasta el año 1870 las funciones ahora desempeñadas por el Registro Civil, eran desenvueltas por los registros parroquiales de la Iglesia católica² ${ }^{2}$.

Por su parte, la vigente Ley del Registro Civil de 8 junio $1957^{3}$ derogó aquella vieja Ley provisional de 1870 y, a su vez, fue desarrollada por el Reglamento ejecutivo, aprobado éste en virtud del Decreto de 14 de noviembre de 1958 . De modo que la regulación actualmente aplicable fue redactada al amparo de los principios de un sistema político y de un modelo de familia que ya no son los imperantes. En justa consecuencia, el ordenamiento registral ha sido sometido a una completa revisión y actualización legislativa y reglamentaria, hasta su casi plena adaptación a los fundamentos de la Constitución de 1978. Revisión en la que, a mayor abundamiento, ha intervenido el Tribunal Supremo, por ejemplo con la controvertida Sentencia de 21 de septiembre de 1999, que derogó por inconstitucionalidad sobrevenida el artículo 47 en su párrafo primero ya que, a juicio del ponente la redacción del precepto que aseveraba que «en la inscripción de nacimiento constará la filiación materna siempre que en ella coincidan la declaración y él parte o comprobación reglamentaria», permitía «interpretaciones reglamentarias que hagan

1 Dice el artículo 325 que «los actos concernientes al estado civil de las personas se harán constar en el Registro destinado a este efecto", para concretar inmediatamente después el artículo 326 que «el Registro del estado civil comprenderá las inscripciones o anotaciones de nacimientos, matrimonios, emancipaciones, reconocimientos y legitimaciones, defunciones, naturalizaciones y vecindad, y estará a cargo de los Jueces municipales u otros funcionarios del orden civil en España y de los Agentes consulares o diplomáticos en el extranjeron.

2 Fundamentalmente sigo, en este estudio, el análisis que del Registro Civil realiza mi Maestro, en los Principios de Derecho Civil 1, Parte General y Derecho de la persona, Madrid, $12^{\mathrm{a}}$ ed., págs. 323 y sigs. Adicionalmente sigo también las apreciaciones y observaciones, generosamente sugeridas por el Profesor Dr. D. Juan $\mathrm{M}^{\mathrm{a}}$ DIAZ FRAILE, Registrador de la Propiedad y Presidente del Consejo de Dirección del CIDDRIM.

${ }_{3}$ Para un exhaustivo estudio de la evolución del Registro y de su normativa, vid., PERE RALUY, Derecho del Registro Civil, I, Madrid, 1962, págs. 80 y sigs. 
[que hacían] depender de la voluntad de la madre, la circunstancia registral de la maternidad ${ }^{4}$.

De modo que, al día de hoy, la legislación reguladora del Registro Civil está constituida por la Ley de 8 de junio de 1957, reformada profundamente en los últimos años. En este sentido, destacaremos entre otras modificaciones recientes, la operada por Ley 3/2007, de 15 de marzo, de la rectificación registral de la mención relativa al sexo de las personas, que da nueva redacción al artículo sexto, sobre la publicidad del Registro ${ }^{5}$, afecta también al artículo 15, sobre los hechos inscribibles, al 54 sobre el nombre y al artículo 93 sobre la rectificación previo expediente gubernativo ${ }^{6}$.

Con todo, este proceso de modernización del Registro no está cerrado, antes bien se encuentra en trámite parlamentario -además del Proyecto de Ley 121/000109, de Jurisdicción voluntaria que incide indirectamente en el Registro Civil de reforma de la Ley del Registro civil en materia de incapacitación, cargos tutelares y administradores de patrimonios protegidos y de la Ley 41/2003, de 18 de noviembre, sobre protección patrimonial de las personas con discapacidad y de modificación del Código civil, de la

${ }^{4}$ Fundamento Jurídico quinto de la Sentencia, siendo ponente ALMAGRO NOSETE, vid., también la STS de 9 de julio de 2001; y el sentido que opone el Tribunal Europeo de Derechos Humanos de Estrasburgo en su sntencia de 13 de febrero de 2003, por cuanto estima ajustado a derecho el parto anónimo (sobre el derecho al desconocimiento de la maternidad, vid., LASARTE ÁLVAREZ, Principios de Derecho civil 6. Derecho de Familia, Madrid, 2006, $5^{\text {a }}$ ed., págs. 323 y sigs.; también RIVERO HERNÁNDEZ, «De nuevo sobre el derecho a conocer el propio origen: el asunto Odièvere», $A C, 2,2003$, págs. 593 a 632 y DURÁN RIVACOBA, «El anonimato del progenitor», Aranzadi Civil, 1, 2004, págs. 2.081 a 2.120 y en Libro Homenaje al Profesor Albaladejo, 1 , págs. 1.361 a 1.410 ).

5 Sobre la protección a la privacidad y el derecho a la intimidad en materia de cambio de sexo, vid., BASTIDA REIJEDO y VILLAVERDE MENÉNDEZ, "Protección de datos y Registro de la Propiedad y Mercantil", La Ley, 6.277, junio de 2005.

6 Téngase en cuenta que esta materia ha sido especialmente controvertida tanto doctrinal como judicialmente, vid., últ. la Sentencia del Juzgado de primera instancia número de los de Valladolid, de 13 de diciembre, de 2004 que ya reconocía el cambio de sexo de mujer a hombre sin necesidad de haberse sometido a una implantación genital. En cuanto a los supuestos de validez del matrimonio entre español/a y extranjero/a del mismo sexo antes de la modificación legislativa señalada, vid., DÍAZ FRAILE, «Exégesis de la doctrina de la DGRN sobre la reforma del Código civil en materia de matrimonio introducida por la Ley 13/2005, de 1 de julio", La Ley, 6.449, 2006.

7 En el momento de revisar este trabajo el texto aprobado por la Comisión de Justicia del Congreso de los Diputados, con competencia legislativa plena, había tenido a su vez entrada en el Senado el día 24 de julio de 2007, estando pendiente de Informe desde el 11 de septiembre. A su vez, la Comisión Redactora del Proyecto, constituida en el seno de la Dirección General de los Registros y del Notariado, fue coordinada por el Registrador y Prof. Dr. D. Juan Ma DÍAZ FRAILE. 
Ley de Enjuiciamiento civil y de la normativa tributaria con esta finalidad $^{8}$ del que haremos expresión más adelante.

\section{LA DEPENDENCIA ORGÁNICA DEL REGISTRO CIVIL AL MINISTERIO DE JUSTICIA: FUNCIONES DE LA DIRECCIÓN GENERAL DE LOS REGISTROS Y DEL NOTARIADO}

Vistos los elementos básicos del sistema regulador del Registro civil español, conviene tener en cuenta el valor y eficacia de las Resoluciones procedentes de la Dirección General de los Registros y del Notariado, dado el valor interpretativo del que están dotadas así como el sólido cuerpo doctrinal que han constituido ${ }^{9}$. En este sentido y para justificar las funciones de esta Dirección general conviene tener presente el contenido del artículo noveno de la Ley del Registro civil ya que destaca la Dependencia orgánica del Registro civil. Advierte dicho precepto que «el Registro civil depende del Ministerio de Justicia. Todos los asuntos a él referentes están encomendados a la Dirección General de los Registros y del Notariado» así como de las Resoluciones de este organismo, cuando haya de resolver los recursos ${ }^{10}$

${ }^{8}$ En cuanto a esta reforma, actualmente sometida al iter parlamentario, la Mesa de la Cámara acordó el pasado día 2 de octubre de 2007, la ampliación del plazo de enmiendas hasta el próximo 9 de octubre de 2007 (BOCG 3/10/2007), por lo que cabe augurar que será objeto de aprobación y publicación con anterioridad a la convocatoria de elecciones generales previstas para el primer trimestre de 2008 y a la consiguiente disolución de las Cámaras y caducidad de los asuntos pendientes (vid., art. 207 del Reglamento del Congreso de los Diputados).

9 Para un análisis detenido del Derecho registral y el valor de sus principios e inscripciones, vid., DÍAZ FRAILE, "La prueba del estado civil ante el Registro de la propiedad. El valor de la inscripción en el Registro civil», Derecho de familia y Registro de la propiedad, 2002, págs. 275 a 340; "Breve esbozo de una teoría general sobre los principios registrales civiles. Particular estudio de la publicidad material del Registro civil», $R C D I, 78,672,2002$, págs. 1.367 a 1.404 ; "El valor jurídico de la inscripción en el Registro civil español", Boletín de Información del Ministerio de justicia, $56,1.916,2002$, págs. 1.489 a 1.512 ; «El principio de publicidad material del Registro civil: particular estudio de la inoponibilidad frente a terceros de los hechos no inscritos», La Ley, 7, 2001, págs. 1.592 a 1.602. Por otra parte vid., MONTSERRAT VALERO, «Notas sobre la eficacia jurídica de la inscripción de la sentencia de incapacitación en el Registro Civil», RDP, 1990, pág. 671.

10 Sobre los recursos, el Reglamento del Registro civil prevé en su artículo 355 que «las resoluciones del Encargado no admitiendo el escrito inicial o poniendo término al expediente son recurribles ante la Dirección General durante quince días, a partir de la notificación. No cabe recurso, remido o queja ante otros órganos» y sigue el 360 señalando que «el Director resolverá sobre la propuesta formulada por el Subdirector. La resolución se dictará en forma análoga al auto, y se publicará en el Boletín de Información del Ministerio de Justicia, en el anuario del Centro directivo y, cuando sea conveniente, en el Boletín Oficial del Estado». 
que se interpongan contra la calificación y resolución del Juez o del Encargado del Registro Civil.

Por tanto, se habrá de tener en cuenta tanto la estructura orgánica básica del Ministerio de Justicia - prevista en el Real Decreto $1.475 / 2004$, de 18 de junio- como las funciones que se atribuyen a esta Dirección general ya que, en particular, determina su artículo 4 sobre la Dirección General de los Registros y del Notariado, lo siguiente: «1. Corresponde a la Dirección General de los Registros y del Notariado: a) La elaboración de los proyectos legislativos sobre las materias de nacionalidad, estado civil y ordenación y funcionamiento del Registro Civil en coordinación con la Secretaría General Técnica, y el conocimiento e informe de cuantos proyectos normativos puedan afectar a dichas materias. b) La tramitación y, en su caso, resolución de expedientes de nacionalidad y los de reconocimiento o denegación de las situaciones que afectan al estado civil de los ciudadanos y su inscripción en el Registro Civil; asimismo, la tramitación y, en su caso, resolución de los recursos gubernativos contra los actos de los titulares del ejercicio de estas funciones, así como el estudio y la resolución de cuantas consultas le sean efectuadas sobre las anteriores materias. c) La planificación de los Registros Civiles, la programación y distribución de los medios materiales y personales precisos para su funcionamiento, así como su organización, dirección e inspección. d) La elaboración de los proyectos legislativos sobre las materias relativas al derecho notarial y registral en coordinación con la Secretaría General Técnica, y el conocimiento e informe de cuantos proyectos normativos pudieran afectar a dichas materias. e) La organización, dirección, inspección y vigilancia de las funciones de la fe pública notarial y las de naturaleza registral en las materias de la propiedad, bienes muebles y mercantiles, la evacuación de cuantas consultas le sean efectuadas sobre aquéllas, así como la tramitación y resolución de los recursos gubernativos contra los actos de los titulares del ejercicio de las citadas funciones. f) La ordenación del gobierno y régimen de los Cuerpos de Notarios y de Registradores, la organización de sus procesos de selección y de provisión de puestos, así como las relaciones ordinarias con sus respectivos organismos profesionales. 2. De la Dirección General de los Registros y del Notariado dependen los siguientes órganos: a) La Subdirección General de Nacionalidad y Estado Civil, a la que corresponde el ejercicio de las funciones a las que se refieren los párrafos a), b) y c) del apartado anterior. b) La Subdirección General del Notariado y de los Registros de la Propiedad y Mercantiles, a la que corresponde el ejercicio de las funciones a las que se refieren los párrafos d), e) y f) del apartado anterior». 
Por tanto, si la Ley Orgánica del Poder judicial declara que el «Registro civil estará a cargo de los Jueces de primera instancia y por delegación de éstos, de los de $\mathrm{Paz}{ }^{11}$, se ha de añadir, para la correcta intelección de lo que ahora se explicará, que las funciones relativas al Registro civil, no se tratan en puridad de una cuestión jurisdiccional. De modo que, aquellos recursos que se interpongan contra las resoluciones en materia registral, se sustanciarán por la Dirección General mencionada pese a no estar integrada esta última en el Poder judicial y tratarse de un órgano administrativo no jurisdiccional en sentido estricto.

\section{EL OBJETO DEL REGISTRO CIVIL Y LOS DIVERSOS TIPOS DE ASIENTOS REGISTRALES: EN PARTICULAR LA INSCRIPCIÓN Y LA INDICACIÓN}

El artículo primero de la Ley del Registro civil determina cuál es el objeto de este Registro público, y lo hace concretando qué tipo de situaciones serán incluidas y publicadas en él. Dice así el artículo 1: «En el Registro civil se inscribirán los hechos concernientes al estado civil de las personas y aquellos otros que determina la Ley.- Constituyen por tanto, su objeto: $1 .^{\circ} \mathrm{El}$ nacimiento. $2 .^{\circ} \mathrm{La}$ filiación. $3 .^{\circ} \mathrm{El}$ nombre y los apellidos. $4 .^{\circ}$ La emancipación y habilitación de edad. $5 .^{\circ}$ Las modificaciones judiciales de la capacidad de las personas o que éstas han sido declaradas en concurso, quiebra o suspensión de pagos. $6 .^{\circ}$ Las declaraciones de ausencia o fallecimiento. $7 .^{\circ} \mathrm{La}$ na-

${ }^{11}$ Artículo 86 de la Ley Orgánica 6/1985, de 1 de julio del Poder judicial; vid., también el artículo 27 de la Ley 38/1988, de 28 de diciembre, de demarcación y de planta judicial. Por su parte, el artículo segundo de la Ley Orgánica del Poder Judicial declara sobre la exclusividad jurisdiccional que «el ejercicio de la potestad jurisdiccional, juzgando y haciendo juzgar lo ejecutado, corresponde exclusivamente a los Juzgados y Tribunales determinados en las leyes y en los Tratados internacionales», si bien en su párrafo segundo y fuera ya de la actividad jurisdiccional añade que «los juzgados y tribunales no ejercerán más funciones que las señaladas en el párrafo anterior, las de Registro civil y las demás que expresamente les sean atribuidas por Ley en garantía de cualquier derecho". En este sentido, ALMAGRO NOSETE recordaba que la jurisdicción consiste «en la actividad desplegada por el Estado para hacer valer la eficacia del ordenamiento jurídico en los casos concretos controvertidos mediante la aplicación judicial del derecho" (ALMAGRO NOSETE, GIMENO SENDRA Y OTROS, Derecho Procesal, I, Valencia, $5^{\text {a }}$ ed., pág. 55). Otra noción puede encontrarse en MONTERO AROCA quien además concreta que como autoriza el artículo 117.4 de la Constitución y recoge el artículo 2.2 de la LOPJ «cabe calificar a un órgano de jurisdiccional, por tener las cualidades precisas, y que sin embargo no ejerza, en un momento determinado, función jurisdiccional" (MONTERO AROCA Y OTROS, Derecho jurisdiccional, Valencia, 2004, 13ª ed., pág. 21 y pág. 38). 
cionalidad y vecindad. $8 .^{\circ}$ La patria potestad, tutela y demás representaciones que señala la Ley. $9 .^{\circ}$ El matrimonio; y $10 .^{\circ}$ La defunción»" ${ }^{12}$.

Si al objeto del Registro se añade que, a su vez, está integrado por los Registros Municipales (a cargo del Juez municipal); los Registros Consulares y el Registro Central ${ }^{13}$ y que, por su parte el Registro Civil se divide en cuatro secciones, "denominadas: la primera Nacimientos y general; la segunda Matrimonios; la tercera, Defunciones; y la cuarta; Tutelas y representaciones legales ${ }^{14}$, no se oculta que algún dato adicional habrá que aclarar ya que, según lo dicho la designación cautelar o preventiva no tiene acceso a la Sección cuarta ${ }^{15}$.

En este sentido, a mayor abundamiento, se ha de decir que los asientos registrales posibles al día de hoy se califican técnicamente como inscripciones (asientos principales con valor permanente y eficacia probatoria privilegiada); anotaciones (provisionales y meramente informativas); notas marginales (son meras notas de coordinación) y, además de las cancelaciones, la novedad introducida por la Ley del Registro civil especialmente relevante a los efectos de estudio, es el asiento denominado «indicación" ${ }^{16}$.

Por tanto, las inscripciones ni presentan idéntico valor, ni tienen tampoco el mismo objeto que las indicaciones; éstas últimas sólo estaban previstas expresamente para la mención marginal del régimen económico matrimonial ya que, como recoge el artículo 77 de la Ley del Registro civil «al margen también de la inscripción del matrimonio podrá hacerse indicación de la existencia de los pactos, resoluciones judiciales y demás hechos que modifiquen el régimen eco-

12 Para un examen más detenido acerca de la naturaleza y objeto del Registro civil español, vid., DÍEZ DEL CORRAL RIVAS, quien advierte que dicho elenco del artículo primero no limita los hechos inscribibles, ya que la fórmula enunciativa no impide que en otros preceptos se autorice, por ejemplo, la inscripción del divorcio (vid., Lecciones prácticas sobre Registro civil, Madrid, 1983, pág. 12).

13 Vid., el artículo décimo de la Ley del Registro civil.

14 Artículo 33 de la Ley del Registro Civil que además concluye declarando que "cada una de las secciones se llevará en libros distintos, formados con las cautelas y el visado reglamentario".

15 En particular y sobre la sección cuarta LINACERO DE LA FUENTE, en su momento, advertía del consenso doctrinal existente sobre el valor declarativo de la inscripción del nombramiento y, en su caso, de modificación del tutor (vid., Derecho del Registro civil, Barcelona, 2002, págs. 249 y sigs.).

${ }_{16}$ Como se ha mencionado en este trabajo se siguen especialmente las apreciaciones doctrinales de mi Maestro, el Prof. LASARTE ÁLVAREZ, en la obra mencionada. También vid., DÍEZ DEL CORRAL RIVAS, Lecciones prácticas sobre Registro civil, cit. y LUCES GIL, Derecho Registral civil, cit. 
nómico de la sociedad conyugal.- Sin perjuicio de lo dispuesto en el artículo 1.322 del Código civil, en ningún caso el tercero de buena fe resultará perjudicado sino desde la fecha de la indicación ${ }^{17}$.

En definitiva, y a la vista del transcrito artículo 223, estos poderes preventivos serán objeto sólo de indicación en el Registro civil. Por tanto, y a falta de otra previsión hemos de integrar analógicamente el ordenamiento registral con las prescripciones del artículo 266 del Reglamento, precepto que decreta el contenido de este asiento ideado, en principio, para la publicidad sobre el régimen económico matrimonial. En este sentido, dice el mencionado artículo: «Las indicaciones registrales sobre régimen económico de la sociedad conyugal se rigen, a falta de reglas especiales, por las de las inscripciones.- Sólo se extenderán a petición de interesado.- No cabe indicación sobre hecho ya inscrito; la practicada se cancelará de oficio con referencia a la inscripción que tendrá, además del propio, el valor de indicación registral.- En la indicación constará la naturaleza del hecho, la denominación, en su caso, del nuevo régimen matrimonial, el documento auténtico o resolución en cuya virtud se extiende el asiento y, en forma destacada, su carácter de indicación.- El título será devuelto al presentante, con nota firmada en la que se consignará el Registro, tomo y folio en que consta la indicación.- En las inscripciones que, en cualquier otro Registro, produzcan las capitulaciones y demás hechos que afecten al régimen económico se expresará en el Registro civil, tomo y folio en que consta inscrito o indicado el hecho. Se acreditarán los datos exigidos por certificación, por el Libro de Familia o por la nota a que se refiere el párrafo anterior, y de no acreditarse se suspenderá la inscripción por defecto subsanable.- En las capitulaciones se consignará siempre el Registro civil, tomo y folio en que consta inscrito el matrimonio celebrado. Si el matrimonio no se hubiese celebrado aún, los otorgantes están obligados a acreditar, en su caso, esos datos al Notario por medio de certificación del matrimonio o de exhibición del Libro de Familia, y el Notario los consignará por nota al pie o al margen de la escritura matriz; el Notario hará a los otorgantes advertencia de esta obligación.- Los Notarios expedirán copias de las estipulaciones que afecten al régimen económico matrimonial en los casos permitidos por la legislación notarial y, en particular, a cualquier solicitante que presente un principio de prueba que le

17 Sobre la indicación del cambio de régimen económico matrimonial, vid., YAÑEZ VIVERO, Las capitulaciones matrimoniales en perjuicio de acreedores y la anotación de embargo sobre bienes exgananciales, Madrid, 2003. Sobre la indicación en general, vid., también PERE RALUY, Derecho del Registro civil, I, cit., pág. 348 y LINACERO DE LA FUENTE, Derecho del Registro civil, cit., pág. 91. 
acredite como titular de algún derecho patrimonial frente a cualquiera de los cónyuges».

\section{LA REFORMA DEL CÓDIGO CIVIL ESPAÑOL EN MATERIA DE PODERES PREVENTIVOS Y AUTOTUTELA}

En términos generales y teniendo en cuenta el elenco de derechos y obligaciones previstos por la Ley 39/2006, de 14 de diciembre, de Promoción de la Autonomía personal y Atención a las personas en situación de dependencia ${ }^{18}$, el alcance técnico de los poderes preventivos y la denominada autotutela consiste, precisamente, en el derecho a «decidir, cuando tenga capacidad de obrar suficiente, sobre la tutela de su persona y bienes, para el caso de pérdida de su capacidad de autogobierno". Sin poder extendernos más de lo estrictamente necesario, esta institución es de reciente factura legal en el sistema jurídico español y, en definitiva, autoriza a que cualquier sujeto en previsión de su futura falta de capacidad, decida y designe, cuando aún la ostente al sujeto que le vaya a representar tanto en el ámbito personal como en el patrimonial ${ }^{19}$.

Por tanto, ha de retenerse que la previsión expresa de la autotutela es fruto de la reforma operada por la Ley 41/2003, de 18 de noviembre, de protección patrimonial de las personas con discapacidad y de modificación del Código civil, de la Ley de Enjuiciamiento civil y de la normativa tributaria con esta finalidad ${ }^{20}$. Gracias a sus pres-

18 En particular, y sobre esta materia, vid., MORETÓN SANZ, "Derechos y obligaciones de los mayores en la nueva Ley de Promoción de la Autonomía Personal y Atención a las Personas en situación de dependencia», Revista del Ministerio de Trabajo y Asuntos Sociales, 70, 2007.

19 Vid., BELLO JANEIRO, "Autotutela e incapacitación voluntaria», Protección jurídica patrimonial de las personas con discapacidad, PÉREZ DE VARGAS MUÑOZ (Coord.), Madrid, 2006, págs. 23 y sigs. También vid., BUSTO LAGO, «La autotutela y la situación de la ausencia no declarada en la Ley 2/2006, de 14 de junio, de Derecho civil de Galicia», $A C$, 9, mayo de 2007 y PERENA VICENTE, «La autotutela: ¿desjudicialización de la tutela? ", La Ley, 6.665, marzo de 2007. También vid., el riguroso estudio de LEONSEGUI GUILLOT, «La autotutela como mecanismo de autoprotección de las personas mayores", La protección de los mayores, LASARTE ÁLVAREZ (Dir.), Madrid, 2007, págs. 143 y sigs.

20 Sobre la intelección de esta norma, vid., MORETÓN SANZ, «Protección civil de las personas con discapacidad: patrimonio especialmente protegido y accesibilidad universal en la Propiedad Horizontal», $R C D I, 687,2005$, págs. 61 a 115; "Apuntes sobre la Constitución Europea y el derecho a la no discriminación de las personas con discapacidad", RDUNED (Revista de Derecho de la UNED), 1, 2006, págs. 247 a 271; "Los derechos de las personas con discapacidad en el ámbito europeo e internacional (Novedades jurídicas en materia de no discriminación por razón de edad, dis- 
cripciones los progenitores pueden designar preventivamente tanto a quienes hayan de integrar estos cargos en favor de sus descendientes como, a mayor abundamiento, cualquier otra disposición relativa a su propia persona y bienes ${ }^{21}$; la Ley incluye otros aspectos relevantes en materia de mandato al permitir que pese a la probable incapacitación del mandante, no resulte per se causa de extinción contractual ${ }^{22}$.

\section{Por tanto, en el conflicto resuelto por la Dirección General de los} Registros y del Notariado que ahora se verá, el problema de fondo no afecta al alcance del nuevo tenor literal del artículo ya que, en puridad, sólo se ha añadido a la ya existente tutela testamentaria prevista

capacidad o dependencia)», Revista de Derecho de Familia de Costa Rica, 2, 2007. También para la distinción entre incapacitación, discapacidad y dependencia, de la misma autora «El nuevo sistema de protección de la persona con autonomía limitada: de la incapacitación judicial a la discapacidad y dependencia», en LASARTE ÁLVAREZ (Dir.), La protección de los mayores, Madrid, 2007.

21 En este sentido reformó el artículo 223, advirtiendo el legislador, en la Exposición de Motivos que antecede a la Ley 41/2003, que «destacada en primer lugar la regulación de la autotutela, es decir, la posibilidad que tiene una persona capaz de obrar de adoptar las disposiciones que estime convenientes en previsión de su propia futura incapacitación, lo cual puede ser especialmente importante en el caso de enfermedades degenerativas.- Efectivamente, si ya los padres pueden adoptar las medidas que consideren oportunas respecto de la persona y bienes de sus hijos menores o incapacitados, no se ven obstáculos para que esta misma posibilidad corresponda a una persona con capacidad de obrar suficiente respecto de sí mismo, para el caso de ser incapacitado.- Esta autotutela se regula introduciendo unos cambios mínimos en el Código civil, consistentes habilitar a las personas capaces para adoptar las disposiciones que considere oportunas en previsión de su propia incapacitación, y ello en el mismo precepto que regula las facultades parentales respecto de la tutela, y en alterar el orden de delación de la tutela, prefiriendo como tutor en primer lugar al designado por el propio tutelado, si bien sin modificar la facultad genérica que corresponde al juez de alterar el orden de delación cuando así convenga al interés del incapacitado pero siempre que hayan sobrevenido circunstancias que no fueron tenidas en cuenta al efectuar la designación.- Además se garantiza, mediante los mecanismos oportunos que el juez que estuviera conociendo de la constitución de la tutela pueda conocer la eventual existencia de disposiciones relativas a la misma, sean de los padres, sean del propio incapaz».

${ }^{22}$ Dice ahora el artículo 1.732 sobre los modos de acabarse el contrato de mandato: «El mandato se acaba: $1 .^{\circ}$ Por su revocación. $2 .^{\circ}$ Por renuncia o incapacitación del mandatario. $3 .^{\circ}$ Por muerte, declaración de prodigalidad o por concurso o insolvencia del mandante o del mandatario.- El mandato se extinguirá, también, por la incapacitación sobrevenida del mandante a no ser que en el mismo se hubiera dispuesto su continuación o el mandato se hubiera dado para el caso de incapacidad del mandante apreciada conforme a lo dispuesto por éste. En estos casos, el mandato podrá terminar por resolución judicial dictada al constituirse el organismo tutelar o posteriormente a instancias del tutor» (para un análisis más completo del contrato de mandato y de sus causas de extinción, vid., por todos, LASARTE ÁLVAREZ, Principios de Derecho civil 3. Contratos, Madrid, 2006, 9. ${ }^{a}$ ed., págs. 370 y sigs.). 
en favor de los progenitores tanto la autotutela como la fórmula de publicidad registral con la obligación del Juez de recabar, en su caso, la existencia de este tipo de poderes. En su virtud y en sentido estricto, la Resolución se circunscribe a dirimir cuál es la fórmula más ajustada al sistema registral y a exigir, en justa consecuencia, cuáles son los datos recabables para la práctica de la indicación de las anteriores circunstancias.

De modo que, previo al análisis del sistema de publicidad registral de los poderes preventivos, conviene traer causa de la redacción íntegra del precepto, especialmente por lo que se refiere a los párrafos segundo, tercero y cuarto, añadidos por la Ley 41/2003. Dice el artículo 223 del Código civil español: «Los padres podrán en testamento o documento público notarial nombrar tutor, establecer órganos de fiscalización de la tutela, así como designar las personas que haya de integrarlos u ordenar cualquier otra disposición sobre la persona o bienes de sus hijos menores o incapacitados.- Asimismo, cualquier persona con la capacidad de obrar suficiente, en previsión de ser incapacitada judicialmente en el futuro, podrá en documento público notarial adoptar cualquier disposición relativa a su propia persona o bienes, incluida la designación de tutor.- Los documentos públicos a los que se refiere el presente artículo se comunicarán de oficio por el notario autorizante al Registro civil, para su indicación en la inscripción de nacimiento del interesado.- En los procedimientos de incapacitación, el juez recabará certificación del Registro civil y, en su caso, del Registro de actos de última voluntad, a efectos de comprobar la existencia de las disposiciones a que se refiere este artículo» ${ }^{23}$.

Por tanto podemos afirmar que, tanto la tutela testamentaria como la autotutela, presentan los siguientes requisitos comunes:

a) Deberán ser verificadas a presencia notarial.

b) Las personas que pretendan realizar estos actos deberán ostentar capacidad de obrar «suficiente» ${ }^{24}$.

${ }^{23}$ Muy especialmente, vid., LEONSEGUI GUILLOT, "Cuestiones prácticas que plantea la autotutela tras su regulación en el Código civil por Ley 41/2003, de 18 de noviembre», en LASARTE ÁLVAREZ (Ed.) Familia, matrimonio y divorcio en los albores del Siglo XXI, Madrid, 2006, págs. 209 a 215 y la bibliografía allí citada.

${ }^{24}$ Para ello téngase en cuenta el juicio notarial de capacidad que deberá evacuar el fedatario público, a quien le corresponde apreciar la capacidad de los otorgantes; en su caso y en defecto de dicha capacidad deberá suspender el acto [vid. TORRES ESCÁMEZ, «Un estudio sobre el juicio notarial de capacidad», $R J N, 34,2000$, págs. 205 a 247; CORRAL GARCÍA, "Algunas consideraciones sobre la protección de las personas mayores por el Derecho civil: en especial, el papel del notario como garante 
c) El Notario autorizante tiene obligación de comunicar de oficio al Registro civil los poderes emitidos

d) El Registro las hará constar como indicación en la inscripción del nacimiento del interesado.

\section{LA DIRECCIÓN GENERAL DE LOS REGISTROS Y DEL NOTARIADO ANTE LA TUTELA PREVENTIVA: LA CONSULTA DE 31 DE MAYO DE 2006 Y LA RESOLUCIÓN DE 19 DE JUNIO DE 2006}

En este trabajo y con estos antecedentes queremos destacar la certera doctrina mantenida en la reciente Resolución de la Dirección General de los Registros y del Notariado de 19 de junio de $2006^{25}$ cuyo sentido había sido anticipado, a su vez, por la Consulta evacuada por el Juez encargado sobre la autotutela y los poderes preventivos, de 31 de mayo de 2006. Por su parte, la Resolución, al resolver un recurso sobre anotación de tutela, clarifica la publicidad que hayan de recibir los cargos tutelares, resultando ser objeto de inscripción su constitución, frente a la mera indicación que de la designación con carácter preventivo, se hará al margen del nacimiento del interesado.

Dos son las cuestiones sometidas a dicha Consulta de 31 de mayo de $2006^{26}$ relativas, respectivamente, al régimen registral de la autotutela y a la inscribibilidad en el Registro Civil o no de los denominados "poderes preventivos». En este sentido, sobre el régimen registral de la autotutela anticipa el sentido de lo que después resuelve la Resolución de 19 de junio de 2006 y en cuanto a los poderes preventivos, advierte el punto segundo de la Consulta que «II. Por lo que se refiere al posible tratamiento registral de las escrituras de apoderamiento otorgadas en contemplación de la eventual incapacitación sobrevenida del mandante, hay que comenzar recordando que en la nueva redacción introducida en el artículo 1.732 del Código civil por la Ley 41/2003, tras establecerse como causas de extinción del man-

de la capacidad de los mayores», RJN, 46, 2003, págs. 27 a 65; también últ. GÓMEZ GARZÁS, «El juicio notarial de capacidad», LASARTE ÁLVAREZ (Dir.), La protección de los mayores, Madrid, 2007 y, por último, MORETÓN SANZ, Régimen jurídico del patrimonio protegido (en prensa)].

25 Publicada en el BOE 239, del viernes de 6 de octubre de 2006.

${ }^{26}$ De nuevo he de dejar constancia de mi agradecimiento al Dr. D. Juan Ma DÍAZ FRAILE quien, generosamente, además de los certeros comentarios y observaciones ya mencionados, me ha suministrado el texto de esta Consulta. 
dato la incapacitación sobrevenida del mandante, se añade como excepción a la eficacia de tal causa extintiva el hecho de que el mandante "hubiera dispuesto su continuación o el mandato se hubiera dado para el caso de incapacidad del mandante apreciada conforme a lo dispuesto por éste'. El precepto agrega que 'en estos casos, el mandato podrá terminar por resolución judicial dictada al constituirse el organismo tutelar o posteriormente a instancia del tutor'. Se trata, por tanto, de un supuesto de excepción a la regla general conforme a la cual el mandato se extingue por la incapacitación sobrevenida del mandante, excepción que responde al fundamento de la propia voluntad de aquél expresada en el momento del otorgamiento del mandato, esto es, en un momento anterior todavía a la declaración judicial su incapacitación.- Con todo, no parece que este régimen especial de extinción del mandato para los casos indicados permita invertir la norma de exclusión de que en materia de poderes establece el artículo 284 del Reglamento del Registro Civil al sancionar que 'no estarán sujetos a inscripción: $3 .^{\circ}$ Los apoderamientos voluntarios', norma que por su carácter general no permite exceptuar de la misma a una modalidad de apoderamientos cuya única particularidad es la de permitir el mantenimiento de su vigencia más allá de la fecha de la incapacitación del mandante, con independencia de la conveniencia de plantear de lege ferenda la revisión de la norma trascrita que por su carácter excluyente impide la publicidad registral de ciertas situaciones jurídicas que podrían verse beneficiadas por la misma ${ }^{27}$ ".

En cuanto a la Resolución de 19 de junio de 2006, en el caso en particular los progenitores designaron preventivamente tutor para su hija así como, para el supuesto de que el órgano tutelar hubiese de ser removido o se excusase del cargo, a otra persona, si bien no tuvieron la cautela de recoger otros datos que los referidos a los nombres y apellidos de los designados. El Notario autorizante ante el que comparecieron, en el ejercicio de las obligaciones que le incumben, da traslado al Registro civil para su indicación en la inscripción de nacimiento de la menor. El Juez encargado del Registro civil deniega la indicación al faltar, a su juicio, la aceptación en el cargo del futuro tutor, así como la ausencia de otros datos adicionales sobre la identidad de los designados.

Por su parte, el Ministerio Fiscal recurre la negativa de efectuar la indicación, fundándose en la innecesariedad del requisito de la aceptación exigido por $\mathrm{SS}^{\mathrm{a}}$. Elevadas las actuaciones a la Dirección Ge-

${ }^{27}$ Apréciese que este texto anticipa, como bien advierte DÍAZ FRAILE, el sentido de la reforma de la Ley del Registro civil mencionada ut supra. 
neral de los Registros y del Notariado, ésta estima parcialmente el recurso interpuesto por el Ministerio Fiscal; mantiene parcialmente la calificación efectuada, toda vez que el régimen aplicable a las indicaciones sobre la autotutela y los poderes preventivos es el previsto para la mención del régimen económico matrimonial, por lo que habrá de constar adicionalmente, los datos o "menciones de identidad" referidos a quienes puedan llegar a ocupar el cargo tutelar.

De modo que la Dirección General concluye, de una parte, que la designación preventiva constituye un negocio jurídico unilateral y no recepticio, por lo que no necesita para que sirva como designación, de la aceptación del destinatario. Por otra parte y resultando aplicable el régimen registral previsto para la indicación del régimen económico matrimonial, han de ser incorporadas a esta designación tutelar las menciones de identidad básicas sobre el destinatario referidas a sus datos personales, edad, domicilio y nacionalidad.

En particular, y por su interés, transcribiremos sus Fundamentos de Derecho tercero, cuarto y quinto que presentan como resultado la estimación parcial del recurso y la confirmación, también parcial de la calificación recurrida. Dice así el Fundamento tercero: «III. La redacción del párrafo primero del artículo 223 del Código civil que contempla la posibilidad de que los padres en testamento o documento público notarial nombren tutor respecto de sus hijos menores o incapacitados procede de la Ley 13/1983, de 24 de octubre, y representa, como ha indicado con acierto la doctrina científica, la más importante concesión a la intervención de la familia en la nueva regulación de las instituciones de guarda y protección establecida por la citada Ley. La designación de tutor o llamamiento a la institución tutelar por los padres de que trata el citado precepto constituye un negocio jurídico de Derecho de familia que requiere una manifestación de voluntad unilateral, si bien que plural en caso de titularidad conjunta de la patria potestad por ambos progenitores, y no recepticia, esto es, no necesitada, para que valga en cuanta tal designación, de la aceptación por parte del designado, y ello sin perjuicio de la necesidad de la posterior constitución de la tutela y de la imprescindible aceptación y toma de la posesión del cargo posterior por parte del designado en quien no concurra causa de excusa una vez formalizada la delación de la tutela (cfr. arts. 231 y 259 Código civil). Por ello no puede confirmarse la calificación del Encargado en la parte relativa a la exigencia de aceptación por parte del designado para el ejercicio de la tutela".

Sigue el Fundamento IV, en los siguientes términos: "Confirma la conclusión anterior la consideración concurrente de que la designa- 
ción de que trata el artículo 223 del Código civil tiene en realidad un carácter preventivo, ya que se hace en un momento previo a la propia constitución de la tutela y, eventualmente, de la propia declaración de incapacitación judicial del hijo y por ello tiene un régimen registral civil diferenciado respecto de las demás resoluciones relativas a los cargos tutelares que son objeto de inscripción, no de indicación como sucede en el caso de las designaciones del artículo 223 del Código civil, y la Sección competente para ello es la Cuarta relativa a las Tutelas y Representaciones legales, en tanto que las indicaciones ahora tratadas se extienden al margen de la inscripción de nacimiento de los interesados, esto es, en la Sección Primera relativa a los $\mathrm{Naci}$ mientos y General. - A este respecto hay que destacar que la Ley 41/2003, de 18 de noviembre, de protección patrimonial de las personas con discapacidad, establece como mecanismo de garantía de efectividad del nombramiento preventivo de tutor (también para el caso de la autotutela) la constancia del mismo en el Registro civil, disponiendo el párrafo segundo del citado artículo 223 del Código civil en su nueva redacción que los documentos públicos en que cualquier persona puede disponer el nombramiento de tutor en previsión de su incapacitación judicial en el futuro o en que los padres designen tutor para sus hijos menores o incapacitados 'se comunicarán de oficio por el notario autorizante al Registro civil, para su indicación en la inscripción de nacimiento del interesado', lo cual supone: a) que la legitimación para solicitar la inscripción, mediante actuación de oficio, corresponde al notario autorizante; b) que el asiento registral que procede para la constancia de lo dispuesto en el documento público es el de 'indicación'; c) que dado que la 'indicación' constituye una modalidad de asiento prevista hasta ahora en nuestro Ordenamiento registral tan sólo en el artículo 77 de la Ley del Registro Civil respecto de las capitulaciones matrimoniales y demás hechos y resoluciones que modifiquen el régimen económico del matrimonio, el régimen jurídico de la constancia de la autotutela y de la designación por parte de los padres de tutor para sus hijos menores o incapacitados se deberá extraer en lo pertinente de los principios que inspiran dicho precepto en cuanto a la mecánica registral y eficacia frente a terceros del asiento; y d) que las circunstancias que se han de hacer constar en dicho asiento deberán ser las que 'mutatis mutandis' vienen recogidas en los modelos actualmente existentes respecto de los nombramientos de cargos tutelares".

Concluye los Fundamentos de Derecho de la mencionada RDGRN de 19 de junio de 2006, con las siguientes afirmaciones: «V. Dada la laguna legal actualmente existente sobre esta última materia respec- 
to de la autotutela y de la designación preventiva de tutor hecha por los padres respecto de sus hijos menores o incapacitados puede tomarse como referencia, incluso en los Registros civiles todavía no informatizados, los modelos aprobados por la Resolución de este Centro Directivo de 25 de enero de 2005, sobre aprobación de la versión 2.0 del programa INFOREG y nuevos modelos de asientos para los Registros civiles informatizados (B.O.E. de 2 de abril de 2005), inspirados en este aspecto en la regulación contenida en los artículos 283 a $289^{28}$ del Reglamento del Registro civil y que, entre otros extremos,

${ }^{28}$ Artículo 283: Son objeto de inscripción los cargos tutelares o de la curatela, sus modificaciones y las medidas judiciales sobre guarda o administración, o sobre vigilancia o control de aquellos cargos.- También son inscribibles los cargos de Albacea, Depositario, Administrador e Interventor judiciales, Síndico o cualesquiera otros representantes que tengan nombramiento especial y asuman la administración y guarda de un patrimonio. Artículo 284: No estarán sujetos a inscripción: $1 .^{\circ}$ La patria potestad y sus modificaciones, sin perjuicio de lo dispuesto para la Sección Primera del Registro Civil y de la inscripción de Administradores nombrados para los menores.$2 .^{\circ}$ Las representaciones de personas jurídicas o de su patrimonio en liquidación.- $3 .^{\circ}$ Los apoderamientos voluntarios. Artículo 285: Tanto el domicilio como el lugar donde estuvieren dentro o fuera de España, la mayor parte de los bienes se acredita a efectos de decidir el Registro competente, por declaración del gestor o representante legal o por cualquier otro medio. Articulo 286: Los cargos se inscriben por testimonio judicial u otro documento público suficiente que acredite la toma de posesión.- La inscripción del administrador del caudal relicto requiere acreditar la aceptación del cargo, en virtud de documento con firma autenticada, no se requiere acreditarla si el mismo nombrado promueve el asiento, lo cual se hará constar entonces con él con su firma. Artículo 287: El folio registral de cada tutela, curatela o representación legal se abrirá con la inscripción primeramente obligatoria relativa a la misma; respecto de las posteriores se aplicará lo establecido sobre inscripciones marginales.- El Encargado del Registro, inmediatamente de practicada la inscripción principal, determinará el número de páginas que ha de comprender el folio, haciéndolo así constar al pie de la última asignada por diligencia en la que se referirá a la inscripción principal.- El organismo tutelar para varios hermanos será objeto de inscripciones únicas.- La inscripción de representación legal del ausente se practicará en el folio abierto para el defensor, si hubiera precedido la de este cargo. Artículo 288: En la primera inscripción se expresarán las menciones de identidad del pupilo o de los que, con anterioridad a la constitución de la representación, eran titulares de los patrimonios a ella sujetos. En los asientos marginales se expresarán sólo los nombres y apellidos.- En la primera o a su margen se hará referencia a la de su nacimiento y a la de incapacitación, declaración de ausencia, muerte u otro hecho que motivó la representación legal.También, por nota marginal se hará referencia, en su día a la inscripción del hecho que implique la extinción de la tutela, curatela o representación, cuando se practique en distinto folio registral. Artículo 289: En la inscripción se expresará especialmente. $1 .^{\circ} \mathrm{La}$ naturaleza de los cargos, y si la representación incumbe a varias personas y en qué medida.- 2. ${ }^{\circ}$ Parentesco con el tutelado o representado, cuando sea la razón del nombramiento.- $3 .^{\circ}$ Facultades de representación conferidas en el título de nombramiento y las limitaciones, igualmente impuestas, si no constan en la inscripción del hecho que motiva la representación legal.- $4 .^{\circ}$ Fecha de toma de posesión.- En la inscripción de modificación se expresará el alcance de ésta. 
requiere que 'en la primera inscripción se expresarán las menciones de identidad del pupilo' (cfr. art. 288 R.R.C.) y también del llamado al cargo tutelar ( vid. modelo 403.03), debiendo entenderse por 'menciones de identidad' las consideradas como tal por el artículo $12 \mathrm{del}$ Reglamento del Registro civil, según el cual 'Las menciones de identidad consisten, a ser posible, en los nombres y apellidos, nombre de los padres, número del documento nacional de identidad, naturaleza, edad, estado, domicilio y nacionalidad', siendo así que en el presente caso falta de especificación de tales menciones de identidad respecto del designado (a excepción de su nombre y apellidos), extremo sobre el cual, en consecuencia, se ha de mantener y confirmar la calificación del Encargado».

\section{REFLEXIONES SOBRE EL DOBLE SISTEMA REGISTRAL EN LA TUTELA PREVENTIVA Y LA AUTOTUTELA: LA DESIGNACIÓN Y EL EFECTIVO NOMBRAMIENTO}

En resumidas cuentas y si se ha elegido esta cuestión, no es sino a la vista del doble sistema registral para los cargos tutelares, sancionado ahora y coexistente gracias a la incorporación al Código civil de la denominada autotutela. En este sentido, ya se ha dicho que con la reforma del artículo 223 del Código civil operada por la Ley 41/2003, de 18 de noviembre ${ }^{29}$, ha sido recogida la posibilidad de designación preventiva de un tutor por y para el propio designante como, en su caso, por parte de los progenitores para sus descendientes.

De modo que con carácter previo al nombramiento e incluso, en previsión del concurso de cualquier circunstancia inhabilitante, el interesado puede designar a quien le vaya a representar legalmente para el caso de que dicha enfermedad o deficiencia llegue a manifestarse y le impida su autogobierno.

Posibilidad técnica que, igualmente, asiste a los progenitores que pueden designar a quien vaya a representar legalmente a sus hijos e hijas menores de edad caso de que concurra alguna circunstancia que, en un futuro, pueda llegar impedir el ejercicio de la efectiva patria potestad sobre sus descendientes.

En buena lógica, la propia naturaleza preventiva de ambas posibilidades sometidas por tanto a la materialización del riesgo que

${ }^{29}$ Recordemos la larga intitulación legal de la norma: «De protección patrimonial de las personas con discapacidad y de modificación del Código civil, de la LEC y de la normativa tributaria con esta finalidad». 
pretenden resolver, provoca que dicha tutela, en puridad, no sea tanto un nombramiento como una mera designación condicionada a dichas circunstancias. Así que, registralmente dicha declaración de voluntad unilateral no recepticia no pasa de ser meramente indicada en la sección primera al margen de la inscripción de nacimiento de los interesados.

Por tanto si el régimen ordinario de cualquier cargo tutelar es de inscripción en la Sección cuarta, el régimen de anotación de estos órganos cuando hayan sido únicamente previstos con carácter cautelar sólo puede ser de indicación al margen ya que, en definitiva, se ha hecho previamente a la propia constitución de la representación legal y, en su caso, al nombramiento efectivo de quien ocupe dicho órgano. Recuérdese que, al día de hoy, tal y como declara la Ley de Enjuiciamiento civil, "cuando se hubiere solicitado en la demanda de incapacitación el nombramiento de la persona o personas que hayan de asistir o representar al incapaz», la "Sentencia que declare la incapacitación o la prodigalidad nombrará a la persona o personas que, con arreglo a la Ley, hayan de asistir o representar al incapaz y velar por él». En su defecto, la Sentencia «que declare la incapacitación determinará la extensión y los límites de ésta, así como el régimen de tutela o guarda a que haya de quedar sometido el incapacitado ${ }^{30}$.

En virtud de lo dicho y basándonos en la pretensión de claridad y rigor que preside en la Resoluciones e Instrucciones de la Dirección General de los Registros y del Notariado, cabe examinar el contenido del Proyecto de Ley 121/000113, en trámite en el momento de redactar estas líneas, de Reforma de la Ley de 8 de junio de 1957, sobre el Registro Civil, en materia de incapacitaciones, cargos tutelares y administradores de patrimonios protegidos y de la Ley 41/2003, de 18 de noviembre, sobre protección patrimonial de las personas con discapacidad y de modificación del Código Civil, de la Ley de Enjuiciamiento Civil y de la normativa tributaria con esta finalidad.

${ }^{30}$ Cfr. artículos 759 y 760 de la Ley de Enjuiciamiento Civil de 2000. Para el resto de los supuestos relativos a la constitución de la tutela y los demás cargos tutelares, habrá de ventilarse en un procedimiento de jurisdicción voluntaria. En la materia, vid., CALAZA LÓPEZ, Los procesos sobre la capacidad de las personas, Madrid, 2007, págs. 210 y sigs. Por otra parte, recuérdese que está actualmente en trámite el Proyecto de Ley 121/000109 de Jurisdicción voluntaria para facilitar la tutela y garantía de los derechos de la persona y en materia civil y mercantil, donde se da nuevo contenido a este régimen (vid., en particular, los arts. 68 a 73 del Proyecto). Por fin y como recuerda el vigente artículo 218 del Código civil «las resoluciones judiciales sobre los cargos tutelares y de curatela habrán de inscribirse en el Registro civil», inscripción que se practicará en virtud de la comunicación de oficio del Juez al Registro. 
En dicho futuro texto reformado no se dedica ningún precepto adicional a aclarar el sentido del régimen jurídico de la constancia registral de la autotutela, seguramente porque tampoco resulta imprescindible a la vista del sentido de la Resolución de 19 de junio de 2006. De modo que a la luz de dicha Resolución los aspectos más destacables son los siguientes:

a) La legitimación para solicitar la inscripción de oficio, corresponde al notario autorizante.

b) El asiento registral que procede es el de indicación.

c) El régimen jurídico de la constancia de la autotutela y de la designación por parte de los progenitores de tutor para sus hijos e hijas menores o incapacitados se deberá extraer, en lo pertinente, de los principios que inspiran la indicación del régimen económico matrimonial en cuanto a la mecánica registral y eficacia frente a terceros del asiento.

d) Las circunstancias que se han de hacer constar en dicho asiento deberán ser mutatis mutandis las recogidas en los modelos actualmente existentes respecto de los nombramientos de cargos tutelares.

De modo que si el régimen de publicidad previsto por el artículo 223 del Código civil es el de indicación, no resulta necesario modificar ni la Ley del Registro Civil ni su Reglamento ejecutivo ya que, en definitiva, basta recurrir al artículo $77^{31}$ de la Ley y aplicarlo extensivamente a esta indicación preventiva.

A mayor abundamiento el mencionado Proyecto de reforma de la Ley del Registro Civil no contempla alteración en el texto del citado artículo 77, conteniéndose adicionalmente la reforma del artículo 38 donde, a petición del Ministerio Fiscal, podría suplirse la negativa a inscribir ya que, la reforma propuesta advierte que "a petición del Ministerio Fiscal o de cualquier interesado, se anotará, con valor simplemente informativo y con expresión de sus circunstancias: $1{ }^{\circ} \mathrm{El}$ procedimiento judicial o gubernativo entablado que pueda afectar al contenido del Registro, incluidas las demandas relativas a procedimientos de modificación de la capacidad. $2 .^{\circ}$ El hecho cuya inscrip-

31 Artículo 77. Inscripción marginal del régimen económico del matrimonio. Al margen también de la inscripción del matrimonio podrá hacerse indicación de la existencia de los pactos, resoluciones judiciales y demás hechos que modifiquen el régimen económico de la sociedad conyugal.- Sin perjuicio de lo dispuesto en el artículo 1.322 del Código civil en ningún caso el tercero de buena fe resultará perjudicado sino desde la fecha de dicha indicación. 
ción no pueda extenderse por no resultar en alguno de sus extremos legalmente acreditado. $3 .^{\circ} \mathrm{El}$ hecho relativo a españoles o acaecido en España que afecte al estado civil según la ley extranjera. $4 .^{\circ}$ La sentencia o resolución extranjera que afecte también al estado civil, en tanto no se obtenga el exequátur $5 .^{\circ}$ La sentencia o resolución canónica cuya ejecución en cuanto a efectos civiles no haya sido decretada aún por el Tribunal correspondiente. $6 .^{\circ}$ La existencia de un guardador de hecho y de las medidas judiciales de control y vigilancia adoptadas respecto del menor o presunto incapaz. $7 .^{\circ} \mathrm{Y}$ aquellos otros hechos cuya anotación permitan la Ley o el Reglamento. En ningún caso las anotaciones constituirán la prueba que proporciona la inscripción». También se propone la reforma del artículo 39 de la LRC en el sentido siguiente: "Al margen de la inscripción de nacimiento se pondrá nota de referencia a las de matrimonio, tutela, representación y defunción del nacido. En estas inscripciones se hará constar, a su vez, referencia a la de nacimiento. Iguales notas de referencia se harán constar respecto de las inscripciones de la Sección IV a que se refiere el artículo 46 bis de esta Ley».

$Y$ ya por último, siquiera como referencia anticipatoria del actual sistema, cabe destacar el actual artículo 251 de la Ley Catalana 9/1998, de 15 de julio del Código de Familia, que según la redacción dada por la Ley 11/1996, de 29 de julio, de modificación de la Ley 39/1991, de 30 de diciembre, de la tutela e instituciones tutelares, creó que el denominado «Registro de Tutelas y Autotutelas», adscrito a la Dirección General de Derecho y Entidades jurídicas.

En este sentido, determina lo siguiente sobre este Registro de Nombramientos Tutelares no Testamentarios: «1. En el Registro de Nombramientos Tutelares no Testamentarios se inscriben las delaciones de las tutelas que han sido otorgadas en uso de las facultades previstas en el artículo 172. 2. A fin de poder inscribir las delaciones y a efectos de la designación de tutor o tutora, los notarios que autoricen escrituras en las que se haga uso de las facultades previstas en el artículo 172 deben dirigir un oficio al Registro a que hace referencia el apartado 1 indicando el nombre, los apellidos, el domicilio y el documento de identidad del otorgante y el lugar y fecha de la autorización y que en tal fecha se ha procedido a dicha designación o anulación, pero sin indicar la identidad de las personas designadas. 3. Las normas relativas a la organización, funcionamiento y publicidad del Registro a que hace referencia el apartado 1 deben dictarse por vía reglamentaria» ${ }^{32}$.

32 Sobre esta materia, vid., TOLDRÁ ROCA, "Aspectos registrales de la tutela en el Derecho civil catalán (Comentario de los artículos 251 y 252 del Codi de Família)», La Notaría, 4, 2002. 


\section{CONCLUSIONES}

En virtud de lo expuesto cabe de nuevo poner de manifiesto la inexistencia de lagunas del ordenamiento jurídico así como su autosuficiencia para cubrir las lagunas de la ley. En el caso en concreto basta recurrir a la integración analógica y al propio sentido común, para destacar que la indicación practicada al margen de la inscripción del interesado deberá recoger las menciones de identidad suficientes para hacer viable, en su caso, que la mera designación pase a convertirse en nombramiento tutelar. Cabe, adicionalmente, destacar el buen juicio de la Dirección General de los Registros y del Notario en la calificación y naturaleza jurídica atribuida a la autotutela y los poderes preventivos, ya que como manifestación de voluntad (plural o individual) unilateral es, a mayor abundamiento, no recepticia al no requerir la designación en sí misma de la aceptación del designado.

Por tanto, a pactos y negocios distintos, publicidad registral también diferente: la indicación para la designación preventiva y la inscripción para la constitución seguida de la aceptación y toma de posesión material del cargo tutelar. Secciones también distintas para dar publicidad de ambos supuestos: la sección primera se reserva para que sea practicada la indicación al margen del nacimiento del interesado y, en su caso, futuro sometido a tutela. Por su parte, la sección cuarta está reservada para la inscripción efectiva de los cargos tutelares. 